\title{
Fever and neutrophilic alveolitis caused by a vanadium based catalyst
}

\author{
O Vandenplas, F Binard-van Cangh, J Gregoire, A Brumagne, A Larbanois
}

Occup Environ Med 2002;59:785-787

Aims: To investigate a worker who experienced systemic and respiratory symptoms when exposed to a vanadium containing powder used as a catalyst in the production of maleic anhydride.

Methods: The investigation included inhalation challenge with the suspected compound combined with monitoring of lung function tests and post-challenge bronchoalveolar lavage.

Results: Exposure to the vanadium containing catalyst for 120 minutes resulted in a sustained decline in forced vital capacity and forced expiratory volume in one second, while the transfer factor for carbon monoxide did not change significantly. The subject developed fever and peripheral blood neutrophilia. Bronchoalveolar lavage performed 48 hours after the end of challenge exposure showed a marked increase in neutrophils $160 \%$ of total cell count).

Conclusions: Exposure to vanadium can cause a metal fume fever-like syndrome associated with neutrophilic alveolitis.

$\mathrm{V}$ anadium is widely used in the manufacture of hard steels and non-ferrous alloys. ${ }^{1}$ Vanadium oxides find further application as catalysts for the production of sulphuric acid and organic acid anhydrides. Occupational exposure to vanadium dust or fumes may also occur during maintenance operations of oil fired boilers in power plants, as fossil fuel ash particulates contains substantial amounts of vanadium. We describe a worker who developed a metal fume fever-like syndrome and neutrophilic alveolitis after exposure to vanadyl pyrophosphate $\left((\mathrm{VO})_{2} \mathrm{P}_{2} \mathrm{O}_{7}\right)$ dust.

\section{CASE REPORT}

A 38 year old man employed by an "industrial cleaning" company was periodically assigned to reactor cleaning and maintenance in a plant producing organic acid anhydrides. At this chemical plant, the tasks entailed removing residue with an industrial vacuum device, cleaning the reactor, and filling reactor tubes with a green powder. This powder, which contained $96 \%$ vanadyl pyrophosphate according to the manufacturer, was used as a catalyst in the conversion of n-butane to maleic anhydride. Reactor maintenance operations were performed approximately every four months and lasted three weeks. On the first day of filling operations, the subject experienced sore throat, nasal congestion, epistaxis, and asthenia. On the next day he developed chest tightness, dyspnoea on exertion, productive cough, and wheezing. His symptomatology resolved over two weeks on sick leave, and treatment with antibiotics and an inhaled bronchodilator prescribed by his general practitioner. The subject was asymptomatic when he was working in other plants, but the symptoms recurred each time he was exposed to the green powder catalyst at the anhydride producing plant.

\section{Main messages}

- Exposure to high levels of vanadium can cause a metal fume fever-like syndrome associated with an acute neutrophilic inflammation of the lower airways.

- The concentration of airborne vanadium causing systemic and respiratory manifestations should be investigated further.

\section{Policy implications}

- Appropriate respiratory protection programmes should be implemented to reduce inhalation of airborne vanadium containing dust.

- The respiratory effects of vanadium based compounds should be surveyed further among exposed workers.

The subject was laid off after five maintenance operations. He was referred to our centre by the Workers' Compensation Board for medicolegal and compensation purposes 18 months after he had lost his job. At that time the subject was asymptomatic. He had smoked 15 cigarettes a day for 17 years. Skin prick test with common inhalant allergens gave negative results. Specific IgE antibodies (Pharmacia CAP system, Uppsala, Sweden) against maleic anhydride were not detected. Specific inhalation challenge with the catalyst was carried out in a $5 \mathrm{~m}^{3}$ ventilated challenge room according to a standardised protocol ${ }^{2}$ and recent guidelines of the European Respiratory Society. ${ }^{3}$ Baseline spirometry showed a forced vital capacity (FVC) of $4.82 \mathrm{l}$ (109\% predicted value) and a forced expiratory volume in one second $\left(\mathrm{FEV}_{1}\right)$ of $3.59 \mathrm{l}(97 \%$ predicted). The transfer factor for carbon monoxide $\left(\mathrm{T}_{\mathrm{L}, \mathrm{CO}}\right)$ measured by the single breath method was $63 \%$ predicted value. On a control day, tipping lactose powder for 30 minutes did not result in significant fluctuations of spirometric values (fig 1). At the end of the control day, the provocative concentration of histamine causing a $20 \%$ fall in $\mathrm{FEV}_{1}\left(\mathrm{PC}_{20}\right)$ was in the non-asthmatic range $(20.5 \mathrm{mg} / \mathrm{ml})$. On the next day, the subject was asked to tip the vanadium containing catalyst (30 $\mathrm{g}$ diluted $1 / 10$ in lactose powder). The duration of exposure was gradually increased $(5,10,15,30$, and 60 minutes) while spirometry was assessed after each exposure. After a 120 minute cumulative exposure to the catalyst, we observed a significant decline in FVC and $\mathrm{FEV}_{1}$, reaching a maximum of $27 \%$ and $35 \%$ from baseline four hours post-challenge. Three hours after the end of exposure, the subject experienced headaches, myalgia, nausea, and fever. His body temperature

Abbreviations: FEV, forced expiratory volume; FVC, forced vital capacity 

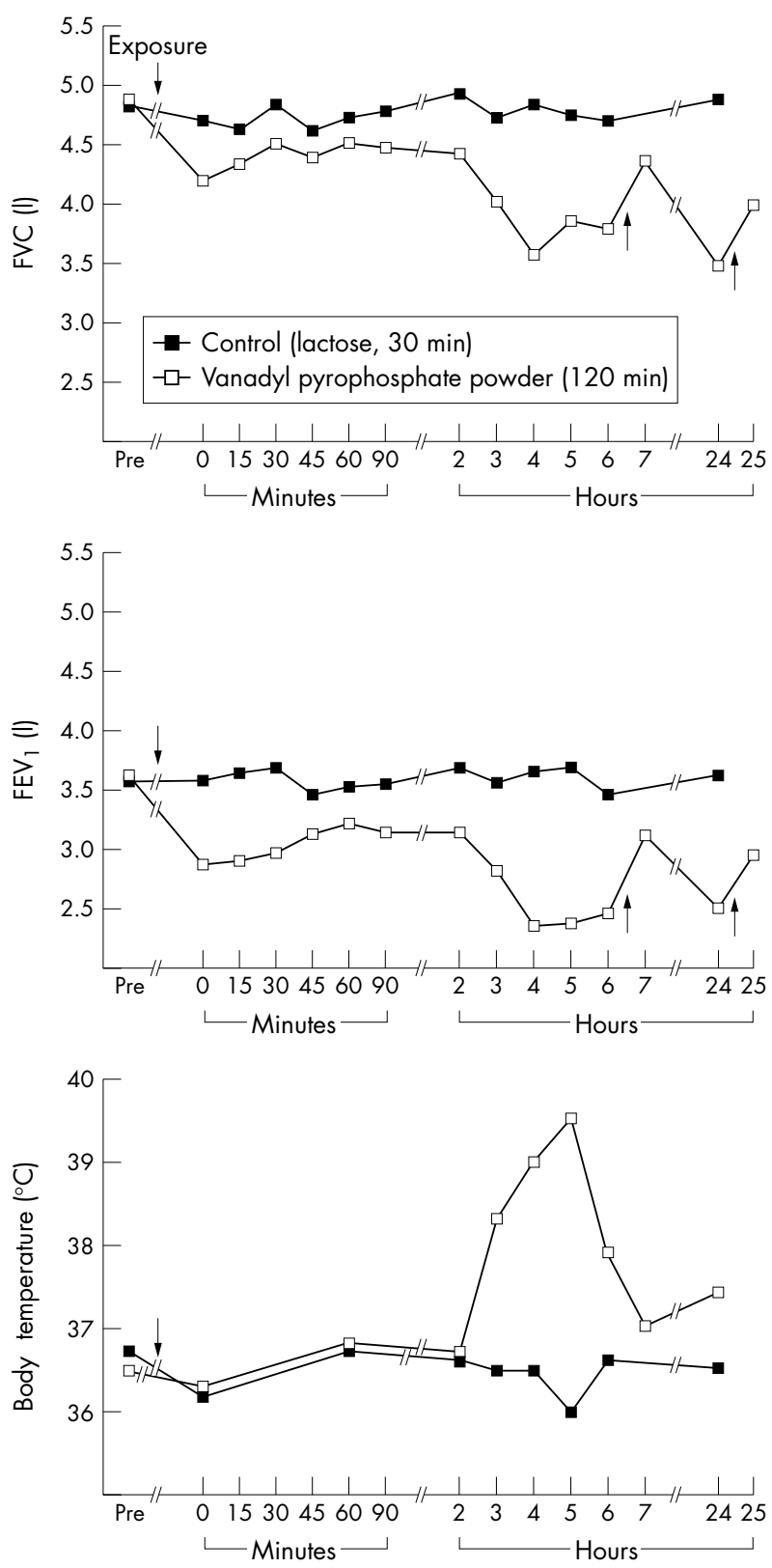

Figure 1 Results of inhalation challenges illustrating the changes in FVC, $\mathrm{FEV}_{1}$, and body temperature after exposure to lactose for 30 minutes and to the catalyst dust containing vanadyl pyrophosphate for 120 minutes. Vertical arrows indicate administration of inhaled salbutamol $(200 \mu \mathrm{g})$.

rose to $39.5^{\circ} \mathrm{C}$ at five hours post-challenge. Blood leucocyte count increased from $9400 / \mathrm{mm}^{3}$ (62\% neutrophils, $1.5 \%$ eosinophils) to $15800 / \mathrm{mm}^{3}$ ( $87 \%$ neutrophils, $0.5 \%$ eosinophils) six hours after the end of the challenge. A chest roentgenogram performed eight hours post-challenge was normal.

$\mathrm{FVC}$ and $\mathrm{FEV}_{1}$ remained lower than baseline values at the 24 th $(-29 \%$ and $-31 \%$, respectively) and 48 th hour $(-23 \%$ and $-20 \%$ ) post-challenge (table 1 ). The subject experienced productive cough and breathlessness when walking. Fever and general malaise vanished within 36 hours. $\mathrm{T}_{\mathrm{L}, \mathrm{CO}}$ did not change significantly 8,24 , and 48 hours after the end of exposure (table 1). Forty eight hours after challenge exposure, reassessment of bronchial responsiveness to histamine showed a $\mathrm{PC}_{20}$ value above $16 \mathrm{mg} / \mathrm{ml}$. Fibreoptic bronchoscopy disclosed a markedly hyperaemic tracheobronchial mucosa. Bronchoalveolar lavage revealed a substantial increase in total cell count $\left(5900 \times 10^{3} / \mathrm{ml}\right)$, including $60 \%$ neutrophils, $39 \%$ macrophages, and $1 \%$ lymphocytes. Because of persisting respiratory symptoms and changes in lung function tests, the subject received oral methylprednisolone for one week and inhaled steroids ( $500 \mu \mathrm{g}$ fluticasone dipropionate twice daily) for three weeks. The subject's symptoms gradually abated over a three week period. Twenty one days after challenge exposure, lung function tests were back to baseline values (table 1). A high resolution computed tomography scan of the lungs showed paraseptal emphysema of the upper lung zones without evidence of interstitial abnormalities.

Concentrations of airborne vanadium during reactor maintenance at the chemical plant could not be measured. These operations were likely to generate high ambient levels of vanadium as the subject noticed that the floor near the reactor was covered with a fine green dust. Approximately fifty 200 litre drums of the vanadium based catalyst were used for filling the reactor's tubes in a poorly ventilated space. The 10 to 12 workers engaged in the maintenance operations wore only paper masks. According to our subject, most of his coworkers complained of nasal irritation and epistaxis, although no other claim for respiratory disorders owing to vanadium had been reported to the Workers' Compensation Board. We reproduced the challenge with the catalyst powder in order to estimate the levels of vanadium that caused the systemic and respiratory reactions in our subject. Inhalable and respirable dusts generated by handling $30 \mathrm{~g}$ of the vanadium based catalyst were collected using personal sampling pumps (MSA Escort Elf, Pittsburgh, Pennsylvania) with a flow rate of 2 $\mathrm{l} / \mathrm{min}$. Particles were collected on $0.8 \mu \mathrm{m}$ cellulose acetate filters (Whatman Nucleopore \# 110609) and analysed using flame atomic absorption spectroscopy. The concentrations of inhalable $\left(13.6 \mathrm{mg} / \mathrm{m}^{3}\right)$ and respirable $\left(4.3 \mathrm{mg} / \mathrm{m}^{3}\right)$ vanadium largely exceeded the permissible exposure limit of $0.05 \mu \mathrm{g} / \mathrm{m}^{3}$.

\section{DISCUSSION}

Inhalation exposure to high levels of vanadium dust resulted in a transient flu-like syndrome similar to metal fume fever, which has been described after exposure to various metals. ${ }^{4}$ In our patient, the systemic reaction was associated with a marked neutrophilic alveolitis and a predominantly restrictive ventilatory defect. Transient pulmonary involvement with radiological infiltrates ${ }^{5}$ and neutrophilic alveolitis ${ }^{6}$ has been occasionally reported in zinc fume fever. Furthermore, Blanc and coworkers ${ }^{7}$ documented a dose related increase in neutrophils and proinflammatory cytokines in bronchoalveolar lavage fluid after exposure to zinc oxide fumes generated by welding galvanised steel. In our patient, respiratory symptoms and functional impairment persisted for at least seven days after challenge exposure to the vanadium based catalyst. This time course was similar to that resulting from exposure at work. Previous case reports suggest that pulmonary reactions associated with zinc fume fever resolve within 24 hours. ${ }^{5}{ }^{6}$ The factors that determined the longer duration of respiratory manifestations in our subject remain unknown. This could be related to the high levels of vanadium generated during inhalation challenge, although similar levels of exposure have been documented during vanadium ore processing and oil fired boiler cleaning. ${ }^{189}$

The respiratory health hazard resulting from occupational and environmental exposure to vanadium compounds remains largely uncertain. ${ }^{1}$ High levels of vanadium oxide dust cause irritation and inflammation of the upper respiratory tract, potentially mediated by recruitment and activation of neutrophils. ${ }^{10}$ Case studies have described the development of acute bronchitis or asthma associated with persistent bronchial hyperresponsiveness in workers exposed to high levels of vanadium pentoxide. ${ }^{8911}$ A causal relation between long term vanadium exposure and chronic airway obstruction has not been substantiated. ${ }^{12}$ In animal experiments, vanadium pentoxide and vanadium containing fuel oil fly ash particles have 
Table 1 Changes in lung function tests after challenge exposure to the vanadium based catalyst

\begin{tabular}{llll}
\hline & $\begin{array}{l}\mathrm{FVC}(\mathrm{I}) \\
\text { (\% predicted) }\end{array}$ & $\begin{array}{l}\mathrm{FEV}(\mathrm{I}) \\
\text { (\% predicted) }\end{array}$ & $\begin{array}{l}\mathrm{T}_{\mathrm{Lcc}} \mathrm{mmol} / \mathrm{min} / \mathrm{kPa} \\
\text { (\% predicted) }\end{array}$ \\
\hline $\begin{array}{l}\text { Baseline } \\
\text { Post-challenge }\end{array}$ & $4.82(109)$ & $3.59(97)$ & $6.44(63)$ \\
$\quad 8$ hours & $4.04(91)$ & $2.91(79)$ & $6.49(63)$ \\
24 hours & $3.42(77)$ & $2.48(67)$ & $6.13(59)$ \\
48 hours & $3.72(84)$ & $2.88(78)$ & $5.79(56)$ \\
7 days & $3.86(87)$ & $2.51(68)$ & $5.73(56)$ \\
21 days & $4.65(105)$ & $3.58(97)$ & $6.81(66)$ \\
\hline
\end{tabular}

FVC, forced vital capacity; $\mathrm{FEV}_{1}$, forced expiratory volume in one second; $\mathrm{T}_{\mathrm{L}, \mathrm{CO}}$, transfer factor for carbon monoxide (single breath method).

been found to provoke bronchoconstriction, enhance nonspecific airway responsiveness, and stimulate the production of cytokines and growth factors, leading to airway remodelling. ${ }^{13}$

To our knowledge, this is the first report of fever and neutrophilic alveolitis caused by a vanadium compound. Further investigation is needed to elucidate the respiratory effects of exposure to vanadium, as this metal has a wide variety of industrial and chemical applications.

\section{ACKNOWLEDGEMENTS}

The authors thank J Boulanger and ML Vanbilsen for their technical assistance. This work was supported by the Services Fédéraux des Affaires Scientifiques, Techniques et Culturelles (Grant SSTC PS/10/ $40)$.

\section{Authors' affiliations}

O Vandenplas, A Larbanois, Service de Pneumologie, Cliniques Universitaires de Mont-Godinne, Université Catholique de Louvain, Yvoir, Belgium

F Binard-van Cangh, J Gregoire, A Brumagne, Fonds des Maladies

Professionnelles, Brussels, Belgium

Correspondence to: $\operatorname{Dr} O$ Vandenplas, Service de Pneumologie, Cliniques Universitaires de Mont-Godinne, B5530 Yvoir, Belgium; olivier.vandenplas@pneu.ucl.ac.be

Accepted 10 April 2002

\section{REFERENCES}

1 Barceloux DG. Vanadium. J Toxicol Clin Toxicol 1999;37:265-78.

2 Vandenplas 0 , Malo JL. Inhalation challenges with agents causing occupational asthma. Eur Respir J 1997;10:2612-29.

3 Sterk P, Fabbri L, Quanjer P, et al. Airways responsiveness. Standardized challenge testing with pharmacological, physical and sensitizing stimuli in adults. Official statement of the European Respiratory Society. Eur Respir J 1993;6(suppl 16):53-83.

4 Nemery B. Metal toxicity and the respiratory tract. Eur Respir J 1990;3:202-19.

5 Malo JL, Malo J, Cartier A, et al. Acute lung reaction due to zinc inhalation. Eur Respir J 1990;3:111-14.

6 Vogelmeier C, Konig G, Bencze K, et al. Pulmonary involvement in zinc fume fever. Chest 1987;92:946-8.

7 Blanc PD, Boushey HA, Wong $\mathrm{H}$, et al. Cytokines in metal fume fever. Am Rev Respir Dis 1993;147:134-8.

8 Levy BS, Hoffman L, Gottsegen S. Boilermakers' bronchitis. Respiratory tract irritation associated with vanadium pentoxide exposure during oil-to-coal conversion of a power plant. J Occup Med 1984;26:567-70.

9 Irsigler GB, Visser PJ, Spangenberg PA. Asthma and chemical bronchitis in vanadium plant workers. Am J Ind Med 1999;35:366-74

10 Woodin MA, Hauser R, Liu Y, et al. Molecular markers of acute upper airway inflammation in workers exposed to fuel-oil ash. Am J Respir Crit Care Med 1998;158:182-7.

11 Musk AW, Tees JG. Asthma caused by occupational exposure to vanadium compounds. Med J Aust 1982;1:183-4.

12 Hauser R, Elreedy S, Hoppin JA, et al. Airway obstruction in boilermakers exposed to fuel oil ash. A prospective investigation. Am J Respir Crit Care Med 1995;152:1478-84.

13 Zhang L, Rice AB, Adler K, et al. Vanadium stimulates human bronchial epithelial cells to produce heparin-binding epidermal growth factor-like growth factor: a mitogen for lung fibroblasts. Am J Respir Cell Mol Biol 2001;24:123-31. 